\title{
An Original Article - A Clinico Pathological Study of Upper Gastro Intestinal Endoscopy in Patients with Dyspepsia
}

\author{
Dr. S. R. Kulkarni ${ }^{1}$, Dr. Ujwal Kumar ${ }^{2}$, Dr. Karan Singhla ${ }^{3}$ \\ ${ }^{1}$ (M.S) General Surgery Professor \& Head Surgery Kims, Karad, Maharashtra, India \\ ${ }^{2}$ MBBS; Resident, Department of Gen Surgery, Kims Karad, Maharashtra, India \\ ${ }^{3}$ MBBS; Resident, Department of Gen Surgery, Kims Karad, Maharashtra, India
}

\begin{abstract}
Aims: The outcome of upper GI endoscopy in dyspeptic patients. The co-relation of alarm symptoms with endoscopy finding. Methods: A total of 120 dyspeptic patients attending surgery OPD of Krishna Hospital, Karad were selected. The case series study was conducted over a period of one and half years. Patient who were willing were subjected to upper GI endoscopy after informed written consent. The endoscopies were performed as per standard protocol and biopsies were taken from suspicious lesions. Observations: age wise distribution of various subject with their specific presentations were observed. Association of alarm symptoms with malignancy was seen. Conclusion: Upper GI endoscopy is a useful diagnostic modality. Dyspepsia is common in male patients than in female; it is more common in age group of 25-55 years of age. The common abnormal endoscopic findings included gastritis, oesophagitis, and duodenitis. Dyspepsia with alarm symptoms increases the risk of malignancy whereas in dyspepsia without alarm symptoms there is reduced risk of malignancy. Alcohol and smoking being major risk factor for dyspepsia. Upper GI endoscopy is a useful diagnostic modality in elucidation of the causes of dyspepsia.
\end{abstract}

Keywords: a study of upper g. i endoscopy in patients with dyspepsia

\section{Introduction}

Dyspepsia is constellation of symptoms, frequently related to food and includes nausea, bloating sensation, epigastric burning sensation, pain, discomfort, indigestion.Dyspepsia affects $1 / 4^{\text {th }}$ of the population of the industrialized countries. Rome 3 criteria defines dyspepsia as one or more symptom such as post prandial fullness, early satiety, epigastric pain or discomfort lasting for at least 4 weeks.Dyspepsia sub type includes reflux like, ulcer like, dismotility like. Dyspepsia with alarm features are associated with gastrointestinal disease such as benign disease like oesophagitis, gastritis, duodenitis, peptic ulcer and gastric malignancies.Alarm features for patient with dyspepsia include age $>50 y r s$, new onset symptoms, sudden weight loss, GI bleed, progessive dysphgia, persistent vomiting, jaundice, mass epigastrium. Upper GI endoscopy is gold standard for diagnosing disease in patient with dyspepsia and is investigation of choice when radiological investigations are negative.Negative endoscopy reduces patient's anxiety and increases satisfaction. Endoscopy helps in early detection and treatment at initial stage of various diseases and thus has better patient outcome. This study is intended to know the profile of upper GI endoscopy findings in dyspeptic patients and look for association of alarm symptoms which helps in early treatment, thereby reducing morbidity and mortality rate.

\section{Materials and Methods}

A total of 120 dyspeptic patients attending surgery opd of KRISHNA HOSPITAL, KARAD were selected. The case series study was conducted over a period of one and half years. Patient who were willing were subjected to upper GI endoscopy after informed written consent. The endoscopies were performed as per standard protocol and biopsies were taken from suspicious lesions.

\section{Inclusion Criteria:}

1. All patients with dyspeptic symptoms, age group of 18 years and above.

2. Patient with alarm symptoms.

3. Patient with previously diagnosed and treated cases of gastric ulcer, duodenal ulcer complicated peptic ulcer, coming with dyspeptic symptoms

\section{Exclusion Criteria:}

1. Patients who are endoscopy negative but have dyspepsia may have other diagnosed disorders.

2. Individuals who had an endoscopy indications other than dyspepsia.

3. Not willing for endoscopy.

4. Age group below 18 years.

Statistical Analysis:

The data was entered in Excel sheet with coding and the same reference.

\section{Observations and Results}

The study of 120 patients who presented with dyspepsia, were taken up for upper GI endoscopy as an initial diagnostic evaluation tool during November 2013 to June 2015. Following were the observations obtained. 


\section{International Journal of Science and Research (IJSR) \\ ISSN (Online): 2319-7064}

Index Copernicus Value (2013): 6.14 | Impact Factor (2015): 6.391

Table1: Distribution of patients according to gender

Sex
Male
Female
Total

No of samples

\begin{tabular}{c|c}
81 & 67.50 \\
\hline 39 & 32.50 \\
\hline 120 & 100.00
\end{tabular}

In our study there are 120 patients of them 81 are males and 39 are females.

Table 2: Age wise distribution of patients

\begin{tabular}{|c|c|c|}
\hline Age groups & No of samples & \% of samples \\
\hline$<=25 y \mathrm{ys}$ & 11 & 2.17 \\
\hline $26-35 \mathrm{yrs}$ & 25 & 10.83 \\
\hline $36-45 \mathrm{yrs}$ & 13 & 25.00 \\
\hline $46-55 \mathrm{yrs}$ & 30 & 20.00 \\
\hline $56-65 \mathrm{yrs}$ & 24 & 14.17 \\
\hline$>=66 \mathrm{yrs}$ & 17 & 100.00 \\
\hline Total & 120 & 47.93 \\
\hline Mean age & & 15.80 \\
\hline SD age & \multicolumn{2}{|c|}{} \\
\hline
\end{tabular}

Table 3: Distribution of patients according to site of endoscopic findings Site of endoscopic findings esophagus only stomach only Duodenum Esophagus and stomach Stomach and duodenum

Esophagus and duodenum Esophagus and stomach and duodenum Normal study Total

\begin{tabular}{|c|c|}
\hline Number & $\%$ \\
\hline 26 & $21.67 \%$ \\
\hline 40 & $33.33 \%$ \\
\hline 15 & $12.5 \%$ \\
\hline 5 & $4.16 \%$ \\
\hline 4 & $3.33 \%$ \\
\hline 4 & $3.33 \%$ \\
\hline 2 & $1.67 \%$ \\
\hline 120 & $20 \%$ \\
\hline
\end{tabular}

Table 4: Distribution of patients according to alarm symptoms

\begin{tabular}{|c|c|c|c|c|c|}
\hline Alarm symptoms & Present & $\%$ & Absent & $\%$ & Total \\
\hline Weight loss & 12 & 10.00 & 108 & 90.00 & 120 \\
\hline Gastrointestinal bleeding & 18 & 15.00 & 102 & 85.00 & 120 \\
\hline Vomiting & 49 & 40.83 & 71 & 59.17 & 120 \\
\hline Dysphagia & 6 & 5.00 & 114 & 95.00 & 120 \\
\hline Odynophagia & 1 & 0.83 & 119 & 99.17 & 120 \\
\hline Jaundice & 2 & 1.67 & 118 & 98.33 & 120 \\
\hline
\end{tabular}

Table 5: Distribution of patients according clinical and endoscopic finding in different organ

\begin{tabular}{|c|c|c|}
\hline & No of subjects & \% of subjects \\
\hline Tenderness & & 97.50 \\
\hline Present & 117 & 2.50 \\
\hline Absent & 3 & 5.00 \\
\hline Mass epigastrium & 6 & 95.00 \\
\hline Present & 114 & 35.00 \\
\hline Absent & & 65.00 \\
\hline Gastritis & 42 & \\
\hline Present & 78 & 20.83 \\
\hline Absent & & 79.17 \\
\hline Oesophagitis & 25 & \\
\hline Present & 95 & 14.17 \\
\hline Absent & & \\
\hline Duodenitis & 17 & \\
\hline Present & 103 & \\
\hline Absent & & \\
\hline Peptic ulcer & 3 & 2.53 \\
\hline Present & 117 & 97.50 \\
\hline Absent & & \\
\hline Duodenal ulcer & 3 & \\
\hline Present & 117 & \\
\hline Absent & 9 & 97.50 \\
\hline Present & & \\
\hline
\end{tabular}

Volume 5 Issue 4, April 2016 


\section{International Journal of Science and Research (IJSR) \\ ISSN (Online): 2319-7064}

Index Copernicus Value (2013): 6.14 | Impact Factor (2015): 6.391

\begin{tabular}{|c|c|c|}
\hline Absent & 111 & 92.50 \\
\hline Carcinoma stomach. & & 3.33 \\
\hline Present & 4 & 96.67 \\
\hline Absent & 116 & \\
\hline Carcinoma periampullary. & & 1.67 \\
\hline Present & 2 & 98.33 \\
\hline Absent & 118 & 100.00 \\
\hline
\end{tabular}

Table 6: Habits associated in patients with dyspepsia

\begin{tabular}{|c|c|c|c|c|c|c|}
\hline Personal History & Present & $\%$ & Absent & $\%$ & Total \\
\hline Alcohol & 76 & 63.33 & 44 & 36.66 & 120 \\
\hline Smoking & 69 & 59.50 & 51 & 42.50 & 120 \\
\hline Pan chewing & 71 & 59.16 & 49 & 40.84 & 120 \\
\hline
\end{tabular}

Table 7: Distribution of patient according to alarm symptoms

\begin{tabular}{|c|c|c|c|c|}
\hline & Normal & Benign & Malignant & Total \\
\hline Dyspepsia with alarm sym. & 27 & 14 & 13 & 54 \\
\hline $\begin{array}{c}\text { Dyspepsia } \\
\text { without alarm sym. }\end{array}$ & 63 & 1 & 2 & 66 \\
\hline
\end{tabular}

Table 8: Distribution of patients according to age with biopsy status

\begin{tabular}{|c|c|c|}
\hline BIOPSY & AGE $<50$ & $>50$ \\
\hline Normal & 63 & 27 \\
\hline Benign & 9 & 6 \\
\hline malignant & 7 & 8 \\
\hline
\end{tabular}

\section{Discussion}

The study "A clinico pathological study of upper GI endoscopy in dyspeptic patients" was undertaken at Krishna hospital, Karad, to know the endoscopic findings of dyspepsia and its co -relation with alarm symptoms. Most patients were in the age group of (25-55)yrs. Mean age was found to be 47.93 years. Comparison with other studies showed similar findings.

\begin{tabular}{|c|c|c|}
\hline Sl .No & Name of study & Mean age in years \\
\hline 1 & Thomson A B R et al $^{31}$ & 45.9 \\
\hline 2 & Ziauddin $^{32}$ & $42.2+-15.7$ \\
\hline 3 & Choomsri p et al & 41 \\
\hline 4 & Present study & 47.93 \\
\hline
\end{tabular}

Endoscopic findings:

gastritis (35\%)

oesophagitis $(20.8 \%)$

duodenitis (14.2\%).

Carcinoma oesophagus (7.5\%)

\begin{tabular}{|c|c|c|}
\hline Sl. No & Name of study & Gastritis \\
\hline 1 & ${\text { Sarwar et } \mathrm{al}^{34}}$ & $13 \%$ \\
\hline 2 & Ziauddin & \\
\hline 3 & Present study & $18 \%$ \\
\hline
\end{tabular}

Gastric Malignancy

Carcinoma Oesophagus - $7.50 \%$

Carcinoma Stomach-3.3\%

Periampullary Carcinoma-1.67\%
Incidences of gastric malignancies observed by various author

\begin{tabular}{|c|c|c|}
\hline Sl. No & Name of study & $\begin{array}{c}\text { Percentage of gastric } \\
\text { malignancy }\end{array}$ \\
\hline 1 & Choomsri p et al $^{33}$ & $1 \%$ \\
\hline 2 & Khan $\mathrm{N} \mathrm{et} \mathrm{al}^{35}$ & $3 \%$ \\
\hline 3 & Ziauddin $^{32}$ & $4 \%$ \\
\hline 4 & Present study & $3.33 \%$ \\
\hline
\end{tabular}

Comparision of endoscopic findings and its association in patients with dyspepsia

\begin{tabular}{|c|c|c|c|}
\hline Groups & Findings & $\begin{array}{c}\text { Sumathi et } \\
\mathrm{al}^{4}\end{array}$ & $\begin{array}{c}\text { Present } \\
\text { study }\end{array}$ \\
\hline \multirow{2}{*}{$\begin{array}{c}\text { Dyspepsia without } \\
\text { alarm }\end{array}$} & Normal & 1223 & 63 \\
\cline { 2 - 4 } & Benign & 1415 & 1 \\
\cline { 2 - 4 } & Malignant & 125 & 2 \\
\hline \multirow{2}{*}{$\begin{array}{c}\text { Dyspepsia with } \\
\text { alarm }\end{array}$} & Normal & 77 & 27 \\
\cline { 2 - 4 } & Benign & 97 & 14 \\
\cline { 2 - 4 } & Malignant & 48 & 13 \\
\hline
\end{tabular}




\section{Conclusion}

Dyspepsia is a common symptom of upper GI disorder. Upper GI endoscopy is a useful diagnostic modality. Dyspepsia is common in male patients than in female; it is more common in age group of 25-55 years of age. The common abnormal endoscopic findings included gastritis, oesophagitis, and duodenitis. Dyspepsia with alarm symptoms increases the risk of malignancy whereas in dyspepsia without alarm symptoms there is reduced risk of malignancy. Alcohol and smoking being major risk factor for dyspepsia. Upper GI endoscopy is a useful diagnostic modality in elucidation of the causes of dyspepsia.

\section{References}

[1] Ikenberry SO, Harrison ME, Lichtenstein D, Dominitz JA, Anderson MA, Jagannath SB, et al. the role of endoscopy in dyspepsia. Gastrointestinal endoscopy 2007, 66(6) 1071-1075.

[2] Sumathi B, Navaneethan U, Jayanti N. Appropriateness of indications for diagnostic upper GI endoscopy in india. Singapore med J 2008; 49(12):970

[3] Ladabaum Uri, Dinh Viam. Rate \& yield of repeat upper GI endoscopy in patients with dyspepsia. World J Gasteroenterology 2010 may 28; 16(20): 2520-2525.

[4] Thomoson A B R et al. the prevalence of clinically significant endoscopic findings in primary care patients with uninvestigated dyspepsia: The Canadian Adult dyspepsia empiric treatment - promt endoscopy (CADET-PE) study. Aliment pharmacol Ther. 2003; 17: 1481-91.

[5] Ziauddin, Endoscopic findings in dyspepsia a prospective study of 200 cases J post grad Med Inst. 2003; 17 (2):235-9.

[6] Choomsri P et al. Upper gastrointestinal endoscopic findings in patient presenting with dyspepsia. Thai $\mathrm{J}$ surg. 2010;31: 7-12.

[7] Sarwar M et al. Endoscopic assessment of dyspepsia. Pak, Armed Forces Med J.2004; 54:48-50.

[8] Khan $\mathrm{N}$ et al. Upper gastrointestinal endoscopic assessment of patients presenting with dyspepsia. JPMI. 2007:21(3):212-6.

[9] Mohd Mubarik et al. diagnostic yield of upper GI endoscopy and ultrasonography in patients of dyspepsia. J K Practitioner 2012:17(4):15-19 